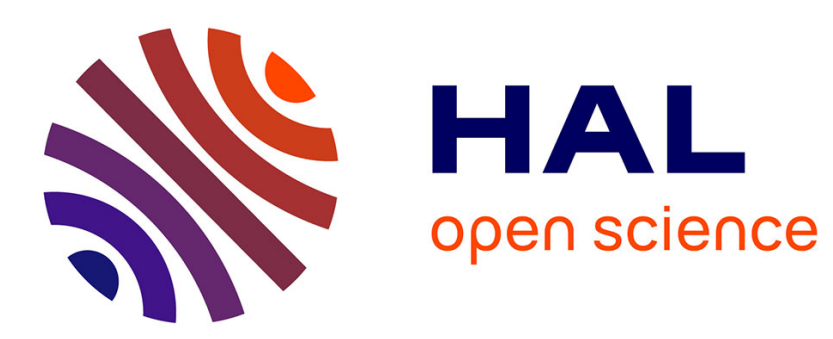

\title{
Beyond Replicator Dynamics: Innovation-Selection Dynamics and Optimal Diversity
}

Karolina Safarzynska, Jeroen C.J.M. van den Bergh

\section{To cite this version:}

Karolina Safarzynska, Jeroen C.J.M. van den Bergh. Beyond Replicator Dynamics: InnovationSelection Dynamics and Optimal Diversity. Journal of Economic Behavior and Organization, 2011, 78 (3), pp.229. 10.1016/j.jebo.2011.01.008 . hal-00989520

\section{HAL Id: hal-00989520 \\ https://hal.science/hal-00989520}

Submitted on 12 May 2014

HAL is a multi-disciplinary open access archive for the deposit and dissemination of scientific research documents, whether they are published or not. The documents may come from teaching and research institutions in France or abroad, or from public or private research centers.
L'archive ouverte pluridisciplinaire HAL, est destinée au dépôt et à la diffusion de documents scientifiques de niveau recherche, publiés ou non, émanant des établissements d'enseignement et de recherche français ou étrangers, des laboratoires publics ou privés. 


\section{Accepted Manuscript}

Title: Beyond Replicator Dynamics: Innovation-Selection Dynamics and Optimal Diversity

Authors: Karolina Safarzynska, Jeroen C.J.M. van den Bergh

PII: $\quad$ S0167-2681(11)00022-9

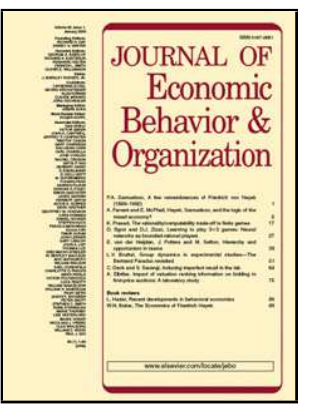

DOI: doi:10.1016/j.jebo.2011.01.008

Reference: $\quad$ JEBO 2668

To appear in: Journal of Economic Behavior \& Organization

Received date: $\quad 1-3-2010$

Revised date: $\quad 24-12-2010$

Accepted date: $\quad 18-1-2011$

Please cite this article as: Safarzynska, K., van den Bergh, J.C.J.M., Beyond Replicator Dynamics: Innovation-Selection Dynamics and Optimal Diversity, Journal of Economic Behavior and Organization (2010), doi:10.1016/j.jebo.2011.01.008

This is a PDF file of an unedited manuscript that has been accepted for publication. As a service to our customers we are providing this early version of the manuscript. The manuscript will undergo copyediting, typesetting, and review of the resulting proof before it is published in its final form. Please note that during the production process errors may be discovered which could affect the content, and all legal disclaimers that apply to the journal pertain. 


\section{Research Highlights}

$>$ We propose a new evolutionary approach to model technological change. > It is based on an extension of replicator dynamics with recombination and mutation. > The framework describes a population of boundedly-rational entrepreneurs. > They invest a fraction of profits in diversification and research on recombinant innovation. > These are captured by mutation and recombination. > We find that mutation enhances diversity of technologies. > Recombination alone may cause a single technology to dominate the market. > When costs follow a learning curve, investing solely in recombinant innovation is cost-minimizing. 


\title{
Beyond Replicator Dynamics:
}

\section{Innovation-Selection Dynamics and Optimal Diversity}

\begin{abstract}
We propose a new evolutionary approach to model technological change based on an extension of replicator dynamics with recombination and mutation. It gives rise to interactive innovation-selection dynamics. The model allows studying the combined effects of selection and variety generation on evolutionary-economic change. The developed framework describes a population of boundedly rational entrepreneurs who decide each period on the allocation of investments in different production technologies. They tend to invest in belowaverage cost technologies, just as under replicator dynamics. In addition, they spend a constant fraction of investments, captured by mutation and recombination rates, on alternative technologies and research on recombinant innovation. As opposed to most previous studies, mutation and recombination are here conceptual variables with a concrete behavioral interpretation, namely describing the decision rules (heuristics) of investors. We compare the dynamics of shares of investments in various technologies for three cases: with constant costs of capital, with costs decreasing steadily and exogenously over time, and with costs depending on the level of cumulative investments. For each model version, we examine under which conditions the coexistence of technological options is feasible and optimal in terms of minimising the average cost of investments.
\end{abstract}

Keywords: bounded rationality, induced technological change, investment theory, learning curve, optimal diversity, recombinant innovation, replicator dynamics.

JEL codes: B52, C61, C62, O32 


\section{Introduction}

Understanding the interaction between selection and variety creation, or innovation, is crucial to the process of technological change. Market selection affects the direction and scope of innovation research, since it determines which technologies and ideas survive and have a good visibility in the market. In evolutionary models of technological change, replicator dynamics is typically employed to capture the relationship between variety and market competition (Saviotti and Mani, 1995). The applicability and relevance of replicator dynamics to model technological evolution has been addressed extensively in the literature (Nelson and Winter, 1982; Bichenhall, 1995; Saviotti and Mani, 1995; Bichenhall et al., 1997; Metcalfe, 1998). Other models of selection dynamics exist, such as best response, Brown-von Neumann-Nash, imitation, mutator, and adaptive dynamics (see Hofbauer and Sigmund, 2003; Nowak and Sigmund, 2004; Safarzynska and van den Bergh, 2010), but they have been rarely applied to model technological change.

Replicator dynamics assumes that above-average fitness strategies (or technologies) diffuse in the population. In fact, replicator dynamics solely addresses the selection process, while the generation of new diversity (innovation) is neglected. This motivates the name “equilibrium selection theory" (Samuelson, 1997). In a number of evolutionary frameworks of technological change, where technological diffusion follows replicator-like dynamics, variety creation is modelled as a process independent of existing variety. As a result, innovation is independent of selection as well (e.g. Iwai, 1984a,b; Silverberg and Lehnert, 1993).

Replicator dynamics is widely used to model adoption of innovation, imitation and social learning in economic applications so as to explains patterns of diffusion of certain types of behaviors or new technologies in a population. However, it ignores the possibility of mistakes, imperfect learning, and costly experimentation with variations and combinations of existing technologies occurring during selection and replication processes. As a result, it entails a bias towards the best performing alternative. In reality, inefficient or less profitable technologies often continue to exist in a market, for a number of reasons. For instance, property rights can prevent or slow down the diffusion of certain innovative solutions; tacit knowledge is difficult to imitate; and exogenous factors cause uncertainty about the profitability of projects (Soete and Turner, 1984).

In this paper, we propose that adding mutation and recombination to replicator dynamics can capture important behavioral and institutional features underlying innovation, that is, experimentation with variation and recombination of existing ideas. Similar to the process of innovation in biological systems, recombination of existing ideas, products or techniques has been recognized by many writers on economic growth and innovation as an 
important mechanism of variety creation in both economics and technology (e.g., Weitzman, 1998; Fleming and Sorenson, 2001; Olsson and Frey, 2002; Tsur and Zemel, 2006). Indeed, recombinant, sometimes referred to as modular innovation, has been an important source of technological change in the past. For instance, the medieval European printers combined six independent existing technologies: paper, movable type, metallurgy, presses, inks and scripts (Diamond, 2005); early mill technology incorporated water mill and sailing solutions (Mokyr, 1990); and more recently, combined cycle gas turbine technology has integrated gas and steam turbine technologies, where heat produced during extracting energy from gas is used to generate electricity with the steam.

Thus far, only in evolutionary-economic models of technological change developed with evolutionary computation techniques mutation and recombination have received much attention (e.g. Birchenhall, 1995; Birchenhall et al., 1997; Yildizoglu, 2002). For instance, Birchenhall et al. (1997) proposed to represent technologies as binary strings, where each bit captures different technical features or components. This is motivated by the fact that most technologies are modular, i.e. they can be decomposed into various modules. In a technology context, individuals can deliberately, and with foresight, change specific components of technologies, which causes technological evolution to be different from natural selection.

In evolutionary-economic models which employ evolutionary algorithms, mutation and recombination typically appear as stochastic factors. Their role differs among alternative evolutionary dialects from being the only variation operator for creating diversity, the only search operator for scanning the parameter space in search for a better solution, a mixture of these two, to not being used at all (Eiben and Smith, 2003). This creates a difficulty in interpreting mutation and recombination operators in an economic context. Birchenhall (1995) and Birchenhall et al. (1997) suggest that recombination and mutation should be thought as capturing individual learning: an individual tries out and evaluates new technologies through experiments, or considers new mixtures of components (recombination) or new variations of existing technological designs (mutation).

To better grasp the feedback mechanisms between the processes of innovation (diversity creation) and selection, we propose a model of technological change which extends replicator dynamics with recombination and mutation rates. This gives rise to a general model of interactive selection-innovation dynamics. The proposed framework builds upon three lines of modelling in theoretical biology: the quasi-species equation (Eigen, 1971; Eigen and Schuster, 1979; Hofbauer, 1985; Schuster and Swetina; 1988; Nowak, 1992; Bull et al., 2005; Nowak, 2006); replicator-mutator dynamics (Hadeler, 1981; Stadler and Schuster, 1992; Bomze and Burger, 1995; Nowak et al., 2001, 2002; Komarowa, 2004; Nowak, 2006); and 'recombination' dynamics (Feldman et al., 1980; Barton, 1995; Boerlijst et al.; 1996; Jacobi and Nordahl, 2006). 
The resulting approach can enrich our understanding of the process of evolutionary change in general, and of economic change and innovation in particular. A behavioraleconomic interpretation of the model is that in each period entrepreneurs tend to invest in capital characterized by an above-average cost. Similarly to vintage capital models, each type of capital is associated with a specific technology (e.g. Iwai, 1984a,b; Silverberg and Lehnert, 1993). In addition, entrepreneurs devote certain (constant) fractions of investments, captured by mutation and recombination, to alternative capital (technologies) and research on recombinant innovation.

Note that we do not simply transfer a model from biology to economics, but adapt it to make it suitable for a socio-economic context. In our model, mutation and recombination are modelled as conceptual variables with concrete behavioral interpretation. They describe heuristic decision rules of boundedly rational investors, i.e. constant fractions of investments allocated among innovative activities. An alternative, non-evolutionary model would require optimizing investments each period. However, this assumes much rationality on behalf of the innovator. In line with the literature on innovation and replicator dynamics we assume limited rationality. On the other hand, describing allocation of investments as following random mutation and recombination (each period) is not realistic. We therefore adapted the biological model by assuming that mutation and recombination are constant over the entire investment period. This is consistent with the common assumption in evolutionary economics that rules of thumbs and routines describe individual behavior (Nelson and Winter, 1982).

In our model, mutation and recombination determine the probability of the emergence of a new technology that is initially absent in the market. This relates to the stylized fact that many innovations have emerged from experimenting with and combining existing ideas and technologies. Mutation in the model can be interpreted as capturing the inability of investors to perfectly assess the profitability of different technologies, costly experimentation, deliberate portfolio diversification, and risky investments in new technologies. In line with the above ideas of Birchenhall, recombination represents individual learning and experimentation through combinations of independent concepts, products or techniques.

We study evolutionary dynamics for three cases (resulting in three model versions): namely, where the unit cost of capital is constant, decreases steadily and exogenously over time, and changes in accordance with the level of cumulative investments. The latter reflects learning-by-doing or learning-by-experience (Arrow, 1962). The analysis of our model provides insights into conditions under which diversification of investments may be costefficient in the long-run. Typically, economists emphasise high costs of maintaining diversity. However, diversity may improve the 'adaptability' of the system, minimize the risks associated with unforeseen contingencies, prevent lock-in of a dominant technology, and be an important source of innovation (van den Bergh, 2008). We derive the conditions under 
which the coexistence of technological options is feasible, and we examine which decision rules, described by mutation and recombination rates, are optimal in terms of minimizing the average cost of investments. The latter is motivated by the fact that the decision how many scarce resources to divert from cheapest technologies towards alternative solutions determines the dynamics of the average cost of investments in different technologies over the investment period.

The remainder of this paper is organized as follows. Section 2 reviews the quasispecies equation, mutator-replicator dynamics and recombination dynamics. In Section 3, we present the new model of replicator dynamics extended with mutation and recombination. In Section 4 , we derive equilibria and investigate their stability, for three different cases. In Section 5, we examine the dynamics of the average cost of investments under different mutation and recombination rates. Section 6 concludes.

\section{Replicator-mutator, quasi-species, and recombinant-dynamics models}

In economic-evolutionary models of technological change, replicator-type dynamics predominates. Replicator dynamics was first formulated by Taylor and Jonker (1978). It describes how the frequencies of various strategies within a population change over time according to their pay-offs (fitness). Since the pay-offs depend on the frequencies of other strategies within a population, this creates a feedback loop mechanism (Samuelson, 1997). Ultimately, the selection process ensures that the fittest strategies (technologies) diffuse in the population. Formally, replicator dynamics can be written as:

$$
\dot{x}_{i}=x_{i}\left(f_{i}-\bar{f}\right),
$$

where $f_{i}$ is a fitness function; and $\bar{f}=\Sigma_{i} x_{i} f_{i}$ is the average fitness.

In evolutionary models of industry dynamics, replicator dynamics determines differential growth of firms given production constraints or dynamics of consumer preferences (Windrum, 2007). Typically, fitness $f_{i}$ is interpreted as profits or productivity, while $x_{i}$ captures (changing) market shares of different products or technologies (e.g., Windrum et al., 1998, 2005), or differential growth of productive capacity of firms (e.g., Soete and Turner, 1984; Metcalfe, 1988).

Replicator dynamics, however, provides an incomplete representation of evolution. It entails a bias towards the currently best-performing alternative(s). In most cases, it rules out the coexistence of variety, unless various strategies achieve exactly the same fitness. According to Young (1998) there is insufficient empirical data to provide evidence for replicator dynamics offering the best description of the process of decision-making or of individuals adapting their behavior in response to others. Similarly, replicator dynamics may 
not grasp all important features of the behavior of firms. It ensures that the most profitable solutions ultimately dominate the market, but ignores the possibility of imperfect learning, of errors occurring during the process of replication, and of costly experimentation during market development. These are, however, important and established aspects of boundedly rational behavior. As argued already in Section 1, they can be captured by mutation and recombination.

Economists using evolutionary methods, both in the study and application of evolutionary games and in neo-Schumpeterian evolutionary economics of technical change, have given surprisingly little attention to mutation and recombination. Notable exceptions are Foster and Young (1990), Canning (1992), Young (1993), and Kandori et al. (1993), who propose models of adaptive learning in the context of repeated $2 \times 2$ games. Here, mistakes by players constantly disturb the process of learning and thus selection dynamics. Independent mutations, introduced at the individual player level, are interpreted as players being incapable of undertaking an optimization calculation or as one of the players being replaced with a new one who knows nothing about the game and thus selects a strategy at random (Kandori, 1993). Alternatively, in Foster and Young (1990) mutations disturb aggregate dynamics. Here, mutation captures variability in pay-offs due to an environmental influence or immigrant players. In these models, examination of the impact of random mutations is an important tool for determining the stability of equilibrium. A unique stationary distribution of strategies is found in the limit distribution as mutation goes to zero, referred to as a 'stochastically stable strategy'.

Within theoretical biology, three alternative models have combined selection and innovation in the most condensed way: namely, replicator-mutator, quasi-species, and recombination dynamics. The simplest possible model allowing for erroneous replications is the quasispecies equation (Eigen, 1971; Eigen and Schuster, 1979; Hofbauer, 1985; Schuster and Swetina; 1988; Bull et al., 2005; Nowak, 2006). The term 'quasi-species' originally referred to an ensemble of similar genomic sequences (RNA molecules) generated by a mutation-selection process. The equation assumes constant fitness selection with the possibility of an erroneous replication defined by a mutation rate. Formally, we have:

$$
\dot{x}_{i}=\sum_{j} x_{j} f_{j} q_{j i}-\bar{f} x_{i},
$$

The mutation matrix $Q=\left[q_{i j}\right]$ is a stochastic matrix, with entry $q_{i j}$ denoting the probability that replication of strategy $i$ will result in strategy $j$, with $\Sigma_{j} q_{i j}=1$. The equation was initially proposed to model the replication of genetic information coded on a (binary) sequence of values. Then, $q_{i j}=p^{H_{i j}}(1-p)^{\left(L-H_{i j}\right)}$, with $p$ the mutation rate per bit, $L$ the 
length of the binary sequence, and $H_{i j}$ the Hamming distance between strings $i$ and $j$ (the number of bits in those strings differ). ${ }^{1}$

For low mutation rates, quasi-species dynamics typically renders a stable coexistence of various strategies. However, for high mutation rates, the shares of strategies start to behave in a chaotic manner. The reason is that, for high mutation rates (above 0.5), the larger the distance between $i$ and $j$, the higher the probability of erroneous replication of $i$ into $j$ :

$$
\frac{\partial q_{i j}}{\partial H_{i j}}=p^{H_{i j}}(1-p)^{L-H_{i j}}[\log (p)-\log (1-p)] .
$$

For low mutation rates (below 0.5), the probability of erroneous replication is lower the larger the distance between strings $i$ and $j\left(L-H_{i j}\right)$.

In the case of quasi-species with no 'back mutation' (causing a return from the mutant to the original strategy), a critical error threshold can be identified beyond which the strategy with the highest fitness will become extinct. It corresponds to the rate at which the replacement rates of different species are equal. Interestingly, if a model incorporates back mutation, there is no strict error threshold (Bull et al., 2005). In the context of economic dynamics, back mutation may capture the decision of a player to return to the old strategy after a period of experimentation with a new strategy.

In a constant selection environment, as is assumed in the quasi-species equation, mutation tends to reduce average fitness. The optimum mutation that maximizes average fitness is then zero (see, Kimura, 1967). However, in a changing environment some positive rate of mutation may be necessary for improving adaptation. Willensdorfer and Nowak (2005) show that with frequency-dependent selection, mutation can enhance the average fitness of the population. This can be captured by an alternative model: namely, replicator-mutator dynamics. It assumes that fitness changes depending on the structure of the population. Replicator-mutator dynamics has been applied in population genetics, biochemistry, and models of language learning (Hadeler, 1981; Stadler and Schuster, 1992; Bomze and Burger, 1995; Nowak et al., 2001, 2002; Komarowa, 2004; Nowak, 2006). It can be written as:

$$
\dot{x}_{i}=\sum_{j} x_{j} f_{j} q_{j i}-\bar{f}_{i} .
$$

Here, $f_{j}$ is a function of frequencies of all strategies present in the population. This equation contains both replicator dynamics and the quasi-species equation as special cases (Nowak, 2006). If the matrix $Q=\left[q_{i j}\right]$ is an identity matrix, the equation reduces to replicator dynamics; if selection is defined on a constant fitness landscape, it becomes the quasi-species equation.

\footnotetext{
${ }^{1}$ The string representation has been employed in evolutionary-economic models to code consumer preferences (Aversi et al., 1997), production designs (Windrum and Birchenhall 1998, 2005), firm routines (Kwasnicka and Kwasnicki, 1992), production rules in Cobweb models (Arifovic 1994, 1995; Dawid and Kopel, 1998), production functions (Birchenhall, 1995; Birchenhall et al., 1997), pricing strategies (Curzon Price, 1997), and strategies in a Prisoner's Dilemma game (Axelrod, 1987; Miller, 1996).
} 
A third relevant model is 'recombination' dynamics. So far, this has been mainly applied to model sexually-reproducing organisms with a constant reproduction rate and no mutation (Feldman et al., 1980; Barton, 1995). Only a few authors combine it with the quasispecies equation, although with the simplification of keeping reproduction rates constant (Jacobi and Nordahl, 2006; Boerlijst et al., 1996). The quasi-species equation with recombination can be described as (Jacobi and Nordahl, 2006):

$$
\dot{x}_{i}=\sum_{l m} V_{k}^{l m} a_{l} x_{l} a_{k} x_{k}-\phi x_{i}
$$

Here, $V_{k}^{l m}=\sum_{i} Q_{k}^{i} T_{i}^{l m}$ with $Q$ a mutation matrix and $T_{k}^{l m}$ a crossover operator that describes the probability that the recombination of parents $l$ and $m$ will result in $k$ offspring. In the case of uniform crossover, offspring $k$ is created by choosing bits with equal probability from one of the parents, and thus $T_{i}^{l m}=2^{-h_{l m}}$ if $O(k, l, m)=1$, and 0 otherwise. $O(k, l, m)$ is equal to 1 at each position where the parents $l$ and $m$ are identical; in this case the same bit appears in the offspring $k$.

The presence of recombination operating on pairs of sequences gives rise to nonlinearity in the growth term. As a consequence, $\phi=\left(\sum_{i} a_{i} x_{i}\right)^{2}$ is imposed to ensure normalization of the population $\left(\sum_{i} x_{i}=1\right)$. For an alternative specification of recombination in quasi-species see also Boerlijst et al. (1996). This study shows that in the quasi-species model, for low mutation rates, recombination enhances overall fitness, while reducing diversity; but for high mutation rates, recombination typically causes chaotic behavior of the system.

\section{A general evolutionary model of selection, mutation, and recombinant innovation}

In this section, we propose a formal model of technological substitution. The basic entities are firms, which produce a homogenous commodity using different production techniques. Each technology is associated with, and requires investments in, specific capital. The evolution of shares of different types of capital, and thus technologies, is modelled using replicator dynamics extended with mutation and recombination. We refer to this as interactive innovation-selection dynamics', which we apply to model the process of capital selection and innovation. First, we develop the general framework for $n$ technologies. In Section 4, we will present a detailed analysis for the case of three technologies. ${ }^{2}$

\footnotetext{
${ }^{2}$ At a conceptual level, our model bears some similarity to the framework developed by Soete and Turner (1984). However, they do not use replicator dynamics to describe market competition as well as
} 
The general framework describes the dynamics of $n$ technologies competing for adoption. We assume an infinite population, in which entrepreneurs invest in different production technologies based on their relative unit cost. In particular, they tend to invest in the below-average cost technologies. Thus, the share of the cheapest technology is expected to increase over time. In addition, entrepreneurs may devote a certain percentage of investments, described by a mutation rate $\mu$, to alternative technologies. The mutation rate can be seen to capture the imperfect, myopic or local nature of search for returns on investment. It can be also regarded as a 'rule of thumb' aimed at devoting a certain fraction of investments for the purpose of diversification and experimentation with new variations. Next, a fraction $r$ of capital, described by the recombination rate, is devoted to fundamental research on recombinant innovation. This process may lead to the emergence of a new technological option that is initially absent in the population.

Changes in the market shares of the already existing technologies are described by (time indices $t$ are omitted to simplify the notation):

$$
\dot{x}_{i}=\sum_{j} x_{j} f_{j} q_{j i}-\sum_{j \neq i} r \delta_{j, i}^{e} \gamma_{i, j}^{e} x_{j} x_{i}-\bar{f} x_{i} \quad \text { for } i=1, . ., m
$$

while changes in the market shares for new emerging technologies $e$, which are initially absent on the market, are as follows:

$$
\dot{x}_{e}=\sum_{j} x_{j} f_{j} q_{j i}+\sum_{j, i} r \gamma_{i, j}^{e} x_{j} x_{i}-\bar{f} x_{e} \quad \text { for } e=m+1, \ldots, n
$$

Here, $m$ denotes the number of existing technologies, and $n$ is the number of new emerging technologies; $x_{i}$ is the share of the capital stock embodying technology $i$ in the total stock of capital used for production in the industry. The above equations consist of three parts:

(i) The expression $\sum_{j} x_{j} f_{j} q_{j i}$ implies that profits $x_{j} f_{j}$ generated by capital $j$ are allocated between the different technologies according to the allocation scheme $Q=\left[q_{j i}\right]$. In particular, the matrix $Q$ describes the fractions (probabilities) of investments in $j$ being directed towards technology $i\left(\sum_{j} q_{j i}=1\right)$. Accordingly, the fraction $q_{j j}=1-\mu$ of profits generated by capital $j$ is being re-invested in this capital, while a share $\mu$ of profits is invested in other types of capital. We assume that investors tend to diversify investments by allocating the fraction $\mu$ of profits equally among other $n-1$ technologies: $q_{j i}=\mu \frac{1}{n-1}$ for $j \neq i$. aspects of our framework. 
(ii) The expression $\sum_{j \neq i} r \delta_{i, j}^{e} \gamma_{i, j}^{e} x_{j} x_{i}$ in equation 6 is a fraction of capital $i$ devoted towards research on recombinant innovation, i.e. on how to combine components from parent technologies $j$ and $i$ to give rise to a new technology $e$. Here, the parameter $r$ is the recombination rate, while $\gamma_{i, j}^{e}\left(=\gamma_{j, i}^{e}\right)$ is a binary variable that takes a value 1 if $i$ and $j$ can be recombined into $e$ and 0 otherwise. This reflects that not all technologies can be recombined. $\delta_{j, i}^{e}$ and $\delta_{i, j}^{e}$ can be interpreted as weights at which technologies $j$ and $i$ are being combined, with $\delta_{j, i}^{e}+\delta_{i, j}^{e}=1$.

According to equation 6 , the fraction of capital $i$ allocated to recombinant innovation depends on the share of capital $j$ devoted to recombinant innovation $\left(r \delta_{j, i}^{e} \gamma_{i, j}^{e} x_{j}\right)$. This is motivated by the fact that technology $e$ is assumed to be modular, i.e. it requires as inputs specific combinations of technologies $i$ and $j$, namely: an amount of $\delta_{j, i}^{e} x_{j}$ of technology $i$ and $\delta_{i, j}^{e} x_{i}$ of technology $j$. To illustrate with an example, combined-cycle gas turbine technologies integrate gas and steam turbines to more efficiently produce electricity, namely by capturing the energy contained in the exhaust gases of the gas turbine to feed into the steam turbine. Here, the gas turbine defines two-thirds and the steam unit one-third of the capacity of the combined-cycle technology (EIA, 2008). One might think of capital $i$ and $j$ as inputs in the production of technology $e$. An entrepreneur, who owns capital $i$ and is interested in devoting some fraction of it to the process of recombinant innovation, will not do so unless capital $j$ (provided by other entrepreneurs) is available for the processes. If one of the parent technologies $i$ or $j$ is absent, the probability of recombinant innovation is zero. Therefore, the entrepreneur is likely to condition the amount of capital $i$, which he intends to devote towards recombinant innovation, on the amount of capital $j$ allocated to the process. As a result of various types of recombinant innovation (given $n$ existing technologies), the shares of technology $e$ increases by $\sum_{j \neq i} r \gamma_{i, j}^{e} x_{i} x_{j}$ in equation $7^{3}$;

(iii) $\bar{f} x_{i}$ is the average fitness in the industry. It is subtracted in equations 6 and 7 to make sure the sum of shares equals one.

We assume that technologies are modular, i.e. composed of many components. We refrain from specifying which dimensions of incumbent technologies or how many of them are being recombined during the process of recombinant innovation. This would result in ad

\footnotetext{
${ }^{3}$ The implicit assumption here is that an amount of $\delta_{j, i}^{e} x_{j}$ of capital $i$ and $\delta_{i, j}^{e} x_{i}$ of capital $j$ are combined to generate a new technology $e$, whose share then increases with $x_{i} x_{j}$. For this reason the $\delta$ parameters do not appear in equation 7.
} 
hoc assumptions. By making a simplifying assumption that technical features from two technologies are recombined in specific proportions $\left(\delta_{i, j}^{e}\right.$ and $\left.\delta_{j, i}^{e}\right)$ we allow for alternative interpretations of technological components and their functionality. The new emerging technology can offer novel services or technical characteristics, or it may fulfil the same functions as its 'parent' technologies but more efficiently.

We define the fitness of a technology as:

$$
f_{i t}=a-c_{i t} .
$$

The parameter $a(\geq 1)$ represents the price of a homogenous product in the industry which does not vary between technologies. One might think of fitness $f_{i t}$ as a mark-up or per unit profits and $f_{i t} x_{i t}$ as total profits associated with the capital embodying technology $i$. An example is electricity, which is a homogenous good produced with different energy technologies, and thus characterised by different costs of production but by a single consumer price.

We consider three alternative cost functions corresponding to different versions of the model, namely: constant costs, costs decreasing steadily and exogenously over time, and dynamics with cost reductions occurring along a learning curve. In case selection operates on constant unit costs:

$$
c_{i t}=c_{i 0},
$$

with $c_{i 0} \in(0,1)$.

Alternatively, unit cost decrease over time according to:

$$
c_{i t}=\frac{c_{i 0}}{g t+b}
$$

with $a, b, c, g$ constants. Here, costs decrease automatically over time.

Finally, according to a third cost specification a unit cost of technology $i$ falls over time in proportion to the level of cumulative investment in its installed capacity, that is along a learning curve (Arrow, 1962):

$$
c_{i t}=c_{i 0} I_{i t}^{-\beta_{i}}
$$

Here, $c_{i 0}$ is the initial cost, $\beta_{i} \in(0,1)$ the learning rate (also referred to as the elasticity or learning index), and $I_{i t}$ cumulative investments in technology $i$ at time $t$. The equation implies that with every doubling of total installed capacity specific costs are reduced by a progress rate (speed of learning) equal to $2^{-\beta}$. Given that we are working in an infinite population framework (due to replicator dynamics), cumulative investments in technology $i$ are defined as being equal to the cumulative shares of investments in this technology:

$$
I_{i t}=\int_{0}^{t} x_{i t} d t
$$


The proposed framework is a rather simple model of technological change, where firms choose techniques so as to minimize the total cost of production, but also direct some of their investments towards diversification and recombinant innovation. No assumption is made about growth of demand, i.e. technological change is purely supply driven. The model allows studying an impact of various behavioral assumptions about entrepreneurs' innovation activities on the process of technological change level.

\section{Model dynamics}

In this section, we study properties of the system (equations 6-11) proposed in Section 3 . $^{4} \mathrm{We}$ reduce the number of dimensions (technologies) from $n$ to three to better grasp core properties of the model. We examine the dynamics resulting from the competition process between three technologies: two exist initially, and one emerges. In Section 4.1 we assume that technologies are characterised by constant costs or by costs that decrease steadily over time, while in Section 4.2 we consider the case of costs that change along a learning curve. In each case, we investigate conditions under which the coexistence of options is feasible. In addition, in Section 5 we examine dynamics of the average cost of investments for each version of the model. Whenever possible, we derive analytical solutions. Otherwise we investigate numerically properties of the system (parameter values are given in Appendix A1). The values of parameters were chosen covering a variety of (relative) initial costs and learning rates of technologies so as to capture a wide spectrum of possible outcomes.

\subsection{Innovation-selection dynamics with constant costs and cost decreasing steadily over time}

Here, we consider a model system for two cases: (i) characterised by a constant unit cost (equation 10a): $f_{i t}=f_{i}=a-c_{i 0}$; and (ii) by unit costs that decrease steadily over time (equation 10b): $f_{i t}=a-\frac{c_{i 0}}{g t+b}$. Note, that (i) is a special case of (ii) for $g=0$ and $b=1$. A version of the model with constant unit costs can be interpreted as describing mature industries, where the potential for cost reduction due to learning or innovative activities (R\&D) is limited. Costs decreasing steadily over time capture technological learning-from-experience.

The three dimensional system is described by the following set of equations:

$$
\begin{aligned}
& \dot{x}_{1 t}=x_{1 t} f_{1}(1-\mu)+0.5 \mu f_{2} x_{2 t}+0.5 \mu f_{3} x_{3 t}-\delta r x_{1 t} x_{2 t}-x_{1 t} \bar{f} \\
& \dot{x}_{2 t}=x_{2 t} f_{2}(1-\mu)+0.5 \mu f_{1} x_{1 t}+0.5 \mu f_{3} x_{3 t}-(1-\delta) r x_{1 t} x_{2 t}-x_{2 t} \bar{f}
\end{aligned}
$$

\footnotetext{
${ }^{4}$ We use Mathematica 4.1 to derive analytical and numerical solutions to the model, as well as to generate graphs (Wolfram Research Inc., 2001).
} 


$$
\dot{x}_{3 t}=x_{3 t} f_{3}(1-\mu)+0.5 \mu f_{1} x_{1 t}+0.5 \mu f_{2} x_{2 t}+r x_{1 t} x_{2 t}-x_{3 t} \bar{f} ;
$$

with $x_{3,0}=0, x_{3 t}=1-x_{1 t}-x_{2 t}$, and $\bar{f}=f_{1} x_{1 t}+f_{2} x_{2 t}+f_{3} x_{3 t}$.

Initially there are two technologies present on the market: $x_{10}, x_{20}>0$ and $x_{10}+x_{20}=1$. Note that we set $\gamma_{12}^{3}=1, \gamma_{23}^{1}=0$, and $\gamma_{13}^{2}=0$ in equations 1,2 and 3 , respectively, assuming that Technologies 1 and 2 may be recombined to give rise to a novel Technology 3. These assumptions also holds for the case considered in Section 4.2.

\section{No recombination}

In the absence of recombination $(r=0)$, the system $12 \mathrm{a}$-c reduces to the quasi-species model, whose properties have been studied extensively in the literature (Nowak et al., 2000). The solution of quasi-species is given by the vector of frequencies $\left(x_{1}, x_{2}, x_{3}\right)$ which corresponds to the largest eigenvalue of the matrix of the linearized system (Nowak, 1992). In a special case, for all technologies characterized by the same fitness: $f_{10}=f_{20}=f_{30}$, the symmetric solution with $x_{i}=1 / n$ always exists and is stable for $\mu$ below a certain threshold level $\mu_{1}(<0.66)$. For mutation equal 0.66 , three technologies coexist with equal shares regardless of their relative unit costs. A second, asymmetric solution, where the share of investment in technology $i$ dominates the investment portfolio, can be identified (i.e. $x_{i}=a$ and $x_{j}=(1-a) /(n-1)$ for $i \neq j$, with $a$ depending on the relative costs), and is stable for $\mu$ above a certain threshold level $\mu_{2}$ (see Nowak et al., 2001; Komarova, 2004; Nowak, 2006). For $\mu_{1}<\mu<\mu_{2}$, one of these solutions emerges depending on the initial conditions. These results hold for both versions of the model with constant costs and costs decreasing over time. This makes sense, as constant costs is a limit case of decreasing costs.

\section{No mutation}

In the absence of mutation $(\mu=0)$ but for a positive value of recombination rate $(r>0)$, the system described by equation 12a-c results in a novel model of replicator dynamics extended with recombination. Table 1 presents four feasible solutions to this system.

Table 1. Solutions to the system $12 a-c$ in the absence of mutation $(\mu=0)$

\begin{tabular}{|l|c|c|c|}
\hline no & $\mathrm{x}_{1}$ & $\mathrm{X}_{2}$ & $\mathrm{X}_{3}$ \\
\hline 1 & 0 & 0 & 1 \\
\hline 2 & 0 & 1 & 0 \\
\hline 3 & 1 & 0 & 0 \\
\hline 4 & $\frac{-f_{1} f_{3}+f_{1} f_{2}+f_{3} f_{2}-\delta r\left(f_{2}-f_{3}\right)}{\delta r\left(f_{2}-f_{1}\right)-\left(f_{2}-f_{3}\right) r-\delta r^{2}+\delta^{2} r^{2}}$ & $\frac{\left(f_{1}-f_{3}\right)\left(-\delta r+r-f_{2}+f_{1}\right)}{\delta r\left(f_{1}-f_{2}\right)+r\left(f_{2}-f_{3}\right)+\delta r^{2}-\delta^{2} r^{2}}$ & $\frac{\left(f_{2}-f_{1}+(\delta r-r)\right)\left(f_{2}-f_{1}+\delta r\right)}{\delta r\left(f_{2}-f_{1}\right)-\left(f_{2}-f_{3}\right) r-\delta r^{2}+\delta^{2} r^{2}}$ \\
\hline
\end{tabular}


Solutions 1-3 in Table 1 correspond to situations where a single technology has taken over the market. The dominance of a new, emerging technology 3 (Solution 1) is stable only if it exhibits the lowest unit costs $\left(c_{3}<c_{1} \text { and } c_{3}<c_{2}\right)^{5}$. Its stability does not depend on the recombination rate. Alternatively, the dominance of one of the two incumbent technologies is determined by the recombination rate and the weights with which the two technologies are combined in the process of recombinant innovation. In particular, Solution $2(0,1,0)$ is stable if $c_{2}<c_{3}$ and $c_{2}<c_{1}+\delta r$, while solution $1(1,0,0)$ is stable if $c_{1}<c_{3}$ and $c_{1}<c_{2}+(1-\delta) r$. For a sufficiently high value of $r$, one of the incumbent technologies will end up dominating the market if it exhibits the lowest unit cost of capital. All in all, the relative costs of technologies determine the shares of technologies and their stability. This suggests that authorities aimed at promoting a specific technology mix (e.g., for sustainable electricity production) may need to intervene using appropriate subsidies or taxes to achieve relative costs that are 'right'.

Interesting from an economic view is that solution 4 corresponds to the coexistence of three technologies. The eigenvalues of this solution (see Table A2 in the appendix) may yield complex numbers depending on the relative costs of technologies, the recombination rate and weights at which Technologies 1 and 2 are combined to give rise to Technology 3. Figure 1 shows how eigenvalues corresponding to Solution 5 change depending on the recombination rate. Here, different stability regimes can be identified: for $r \in(0,0.025)$, one of the eigenvalues is real and negative, and the other two are complex with negative real parts, so the fixed point is stable. For $r \in(0.025,0.2)$ three eigenvalues are real and negative so the fixed point is also stable. Finally, for $r \in(0.2,1)$ two of the eigenvalues are real and negative, while one is real and positive, so that the fixed point is unstable. This implies that coexistence of different technologies on the market is possible and persistent only for low values of recombination, i.e. below 0.2 . In fact, it is even unrealistic to expect that entrepreneurs would invest larger shares of their profits in $R \& D$ on recombinant innovation, given that it is a process with an uncertain outcome. Moreover, a large fraction of profits devoted towards research on recombinant innovation may wipe out incumbent technologies from the market.

\footnotetext{
${ }^{5}$ See the Appendix 2.
} 


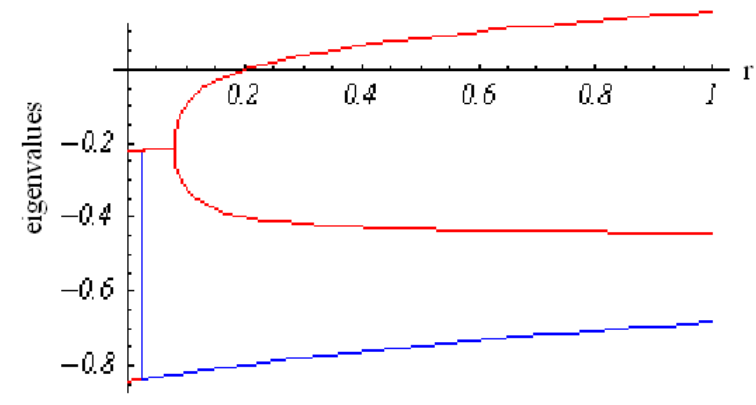

Figure 1. Eigenvalues corresponding to Solution 5 for $a=1, c_{10}=0.1, c_{20}=0.2, c_{30}=0.4$, and $\delta=0.5{ }^{6}$

Where costs decrease steadily with time, solutions can be obtained by substituting fitness functions described by equation 10(b) into the solutions in Table 1. This implies treating time as "frozen". 7 Solution 4 corresponding to the coexistence of three options, in the limit, as $t$ goes to infinity, approaches the point $(0,0,1)$ with technology 3 dominating the market in the long run. Therefore, when costs decrease steadily, investment in recombinant innovation alone prevent the coexistence of options over time.

\section{Mutation and recombination}

Below, we examine numerically the trajectories of shares of investments in different technologies in the presence of mutation and recombination. This relates to the fact that in the presence of recombination and mutation, the process of innovation-selection dynamics has 8 possible solutions whose stability and feasibility is difficult to assess analytically. The solutions are complex functions of unit costs and other parameters. ${ }^{8}$ For the model version with constant unit costs, the phase diagrams in Figure 2a present ten trajectories of shares of technologies 1 and $2\left(x_{1 t}, x_{2 t}\right)$, while the diagrams in Figure $2 \mathrm{~b}$ do this for technologies 1 and 3 $\left(x_{1 t}, x_{3 t}\right)$. Parameter values $\left(a, \delta, r, \mu, c_{10}, c_{20}\right.$, and $\left.c_{30}\right)$ associated with different trajectories in each diagram are summarized in the Appendix (Table A1). Their values were chosen to depict the relevant range of possible dynamic patterns of $\left(x_{1 t}, x_{2 t}, x_{3 t}\right)$. Initial values of state variables are $x_{10}=x_{20}=0.5$, and $x_{30}=0$ in each case. The presence of mutation and recombination always results in the coexistence of three technological options (Figures $2 \mathrm{a}$ and $2 \mathrm{~b}$ ). The diversity of technologies is stable for a wide variety of combinations of parameter values (i.e. relative

\footnotetext{
${ }^{6}$ This parameter values captures a case of a new, emerging technology with an initially high unit cost competing for adoption with two incumbent technologies with relatively low unit costs.

${ }^{7}$ This does not always allow for the correct solution to be derived (Wiggins, 2003). To avoid errors, the function $x(t)$ should be found, and its asymptotic properties examined. However, it is not always possible to derive an explicit function $x(t)$. Here, the proposed system involves products of shares $x_{i}$ and time $t$, so that there is no simple (linear) separation of the solutions to provide time-invariant equations and oscillations free of initial conditions.

${ }^{8}$ We do not provide the expressions here because of their complexity and length.
} 
costs, recombination and mutation), for both versions of the model: with constant costs and costs decreasing steadily over time. In the latter case, points corresponding to different solutions tend to show more clustering (we do not show these phase diagrams here) than in the case of constant costs (Figure 2). This implies that in the version of the model with costs decreasing steadily over time, different investment strategies are likely to result in similar outcomes in terms of the diversity of technologies present in the market.

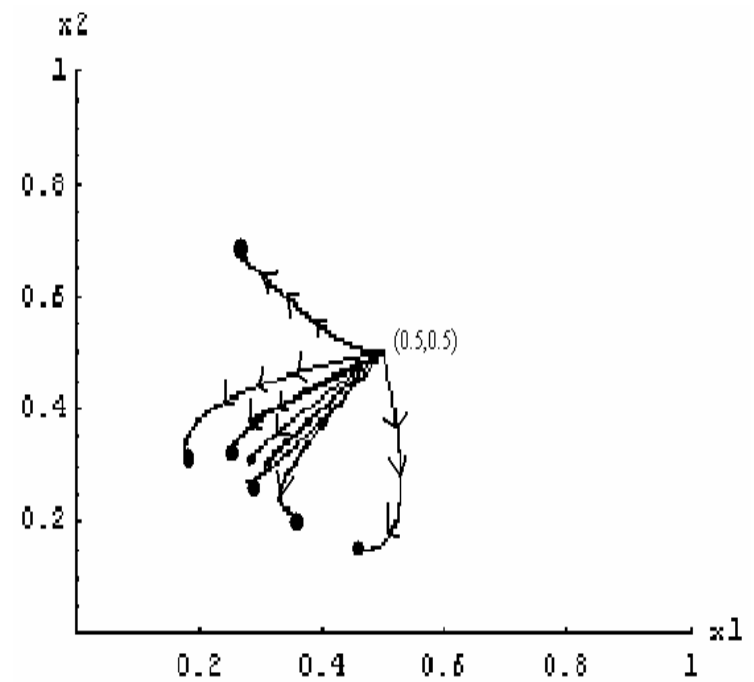

(a) Phase diagram $\left(x_{1 t}, x_{2 t}\right)$ in the presence of mutation and recombination

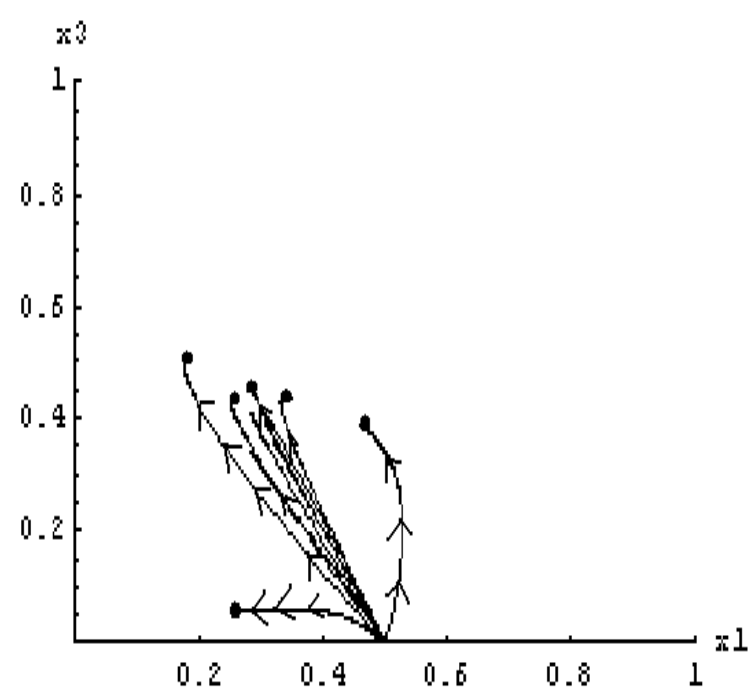

(b) Phase diagram $\left(x_{1 t}, x_{3 t}\right)$ in the presence of mutation and recombination

Figure 2. Phase diagrams for initial conditions: $x_{10}=0.5 x_{20}=0.5$, and $x_{30}=0$.

All in all, investments in recombinant innovation alone typically rules out coexistence of a variety of technologies in production - regardless of whether investments in diversification are absent or not. Investments in diversification are required to prevent lock-in to a single technology. If entrepreneurs invest in both diversification and recombinant innovation, the coexistence of options on the market is guaranteed. In this case, technology 3 captures larger shares than in the absence of investments in diversification.

\subsection{Innovation-selection dynamics with costs changing along a learning curve}

In this section, we consider the system with cost reductions occurring along a learning curve.

Here, technological fitness is expressed as: $f_{i t}=a-c_{i 0}\left(\int_{0}^{t} x_{i t}\right)^{-\beta_{i}}$. The system then becomes: 


$$
\begin{aligned}
& \dot{x}_{1 t}=x_{1 t}\left(a-c_{10}\left(\int_{0}^{t} x_{1 t} d t\right)^{-\beta_{1}}\right)(1-\mu)+0.5 \mu\left(a-c_{20}\left(\int_{0}^{t} x_{2 t} d t\right)^{-\beta_{2}}\right) x_{2 t}+0.5 \mu\left(a-\left(c_{30} \int_{0}^{t} x_{3 t} d t\right)^{-\beta_{3}}\right) x_{3 t} \\
& -\delta r x_{1 t} x_{2 t}-x_{1 t} \bar{f} \\
& \dot{x}_{2 t}=x_{2 t}\left(a-c_{20}\left(\int_{0}^{t} x_{2 t} d t\right)^{-\beta_{2}}\right)(1-\mu)+0.5 \mu\left(a-c_{10}\left(\int_{0}^{t} x_{1 t} d t\right)^{-\beta_{1}}\right) x_{1 t}+0.5 \mu\left(a-c_{30}\left(\int_{0}^{t} x_{3 t} d t\right)^{-\beta_{3}}\right) x_{3 t}(13 \mathrm{~b}) \\
& -(1-\delta) r x_{1 t} x_{2 t}-x_{2 t} \bar{f} \\
& \dot{x}_{3 t}=x_{3 t}\left(a-c_{30}\left(\int_{0}^{t} x_{3 t} d t\right)^{-\beta_{3}}\right)(1-\mu)+0.5 \mu\left(a-c_{10}\left(\int_{0}^{t} x_{1 t} d t\right)^{-\beta_{1}}\right) x_{1 t}+0.5 \mu\left(a-c_{20}\left(\int_{0}^{t} x_{2 t} d t\right)^{-\beta_{2}}\right) x_{2 t} \\
& +r x_{1 t} x_{2 t}-x_{3 t} \bar{f}
\end{aligned}
$$

Unlike in the previous section, derivation of general results here is difficult since technology fitness depends on cumulative shares of technologies, which implies fitnessdependent selection. The resulting system is therefore far too complicated to derive analytical solutions, even in the absence of mutation; below, we investigate the properties of this system numerically. Typically, the solutions are complex numbers. Phase diagrams in Figures 3 a to 3f show the trajectories of the real parts of the solutions for the same parameter values as in the phase diagrams in previous section (see Appendix A1). Figures 3a, 3c and $3 \mathrm{e}$ show, respectively, the trajectory of solutions $\left(x_{1}, x_{2}\right)$ in the absence of mutation, in the absence of recombination, and in the presence of mutation and recombination. Analogously, Figures 3b, $3 \mathrm{~d}$ and $3 \mathrm{f}$ depict phase diagrams for the trajectories of $\left(x_{1}, x_{3}\right)$.

The results suggest that the dominance of a single technology occurs in the absence of mutation (Figures 3a and 3b), which is a similar result to the one obtained in the previous section. Thus, investments in recombinant innovation alone typically render the dominance of the single technology, reducing diversity of technologies on the market. In the presence of investments in diversification, regardless of whether recombination is present or not (Figures $3 \mathrm{c}-\mathrm{e})$, model dynamics lead to the coexistence of three technological options. The presence of investments in recombinant innovation causes technology 3 to capture a larger share of the market than in the case such investments are absent.

These results suggests that if entrepreneurs invest all their profits only in recombinant innovation, the market is likely to become locked-in into a single technology. This may not be a desirable outcome: a new technology may become dominant before it is mature enough, while a reduced diversity of technologies would limit the scope for future innovation activities and the improvement and growth of a possibly better alternative. Investments in diversification help to avoid such a lock-in. The question then arises how costly will be diversification for the different model versions, which we examine in the next section. 

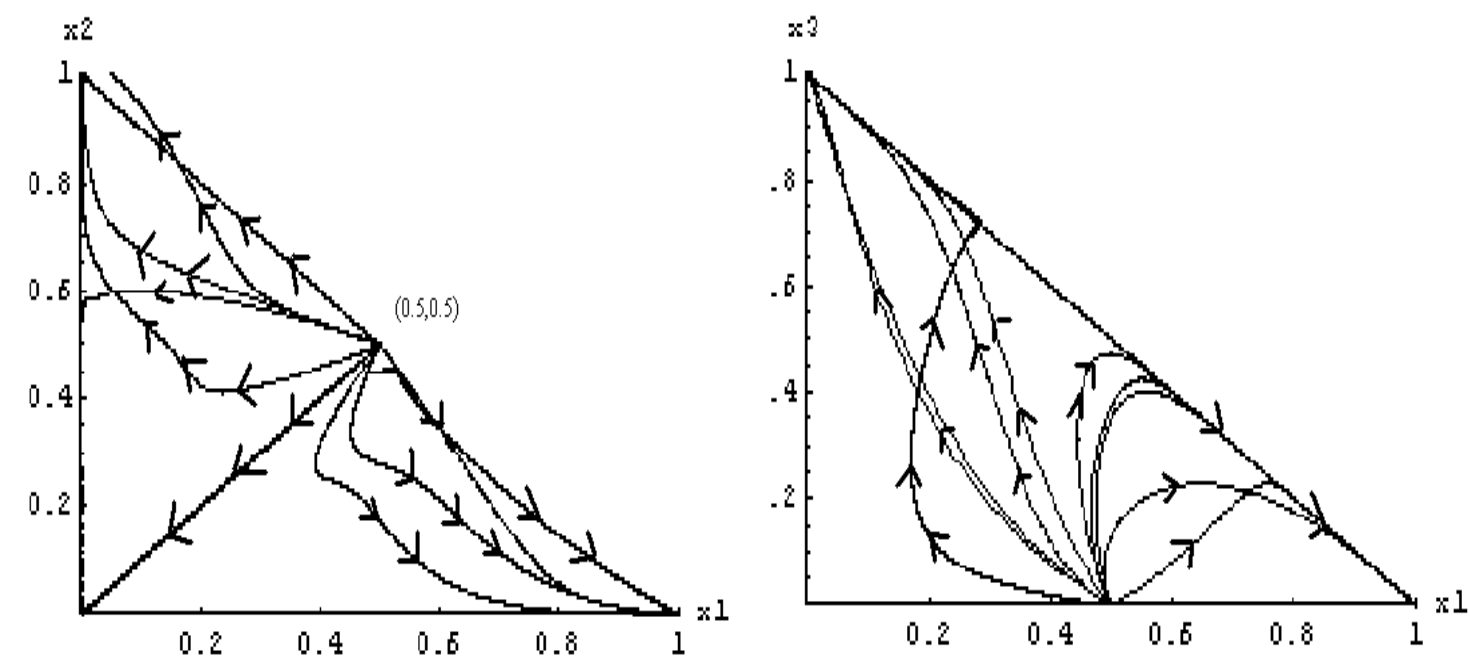

(a) Phase diagram $\left(x_{1 t}, x_{2 t}\right)$ in the absence of mutation $(\mu=0)$

(b) Phase diagram $\left(x_{1 t}, x_{3 t}\right)$ in the absence of mutation $(\mu=0)$
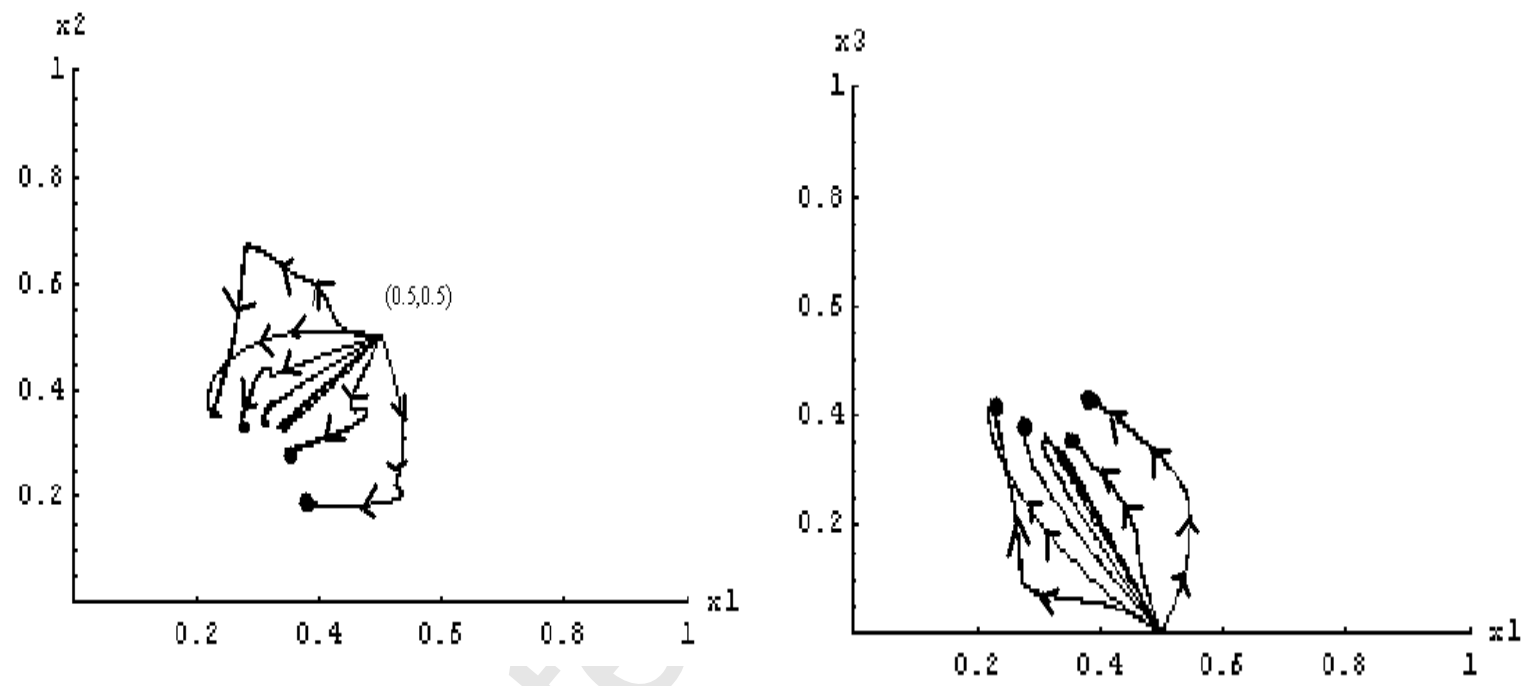

(c) Phase diagram $\left(x_{1 t}, x_{2 t}\right)$ in the absence of recombination

(d) Phase diagram $\left(x_{1 t}, x_{3 t}\right)$ in the absence of recombination
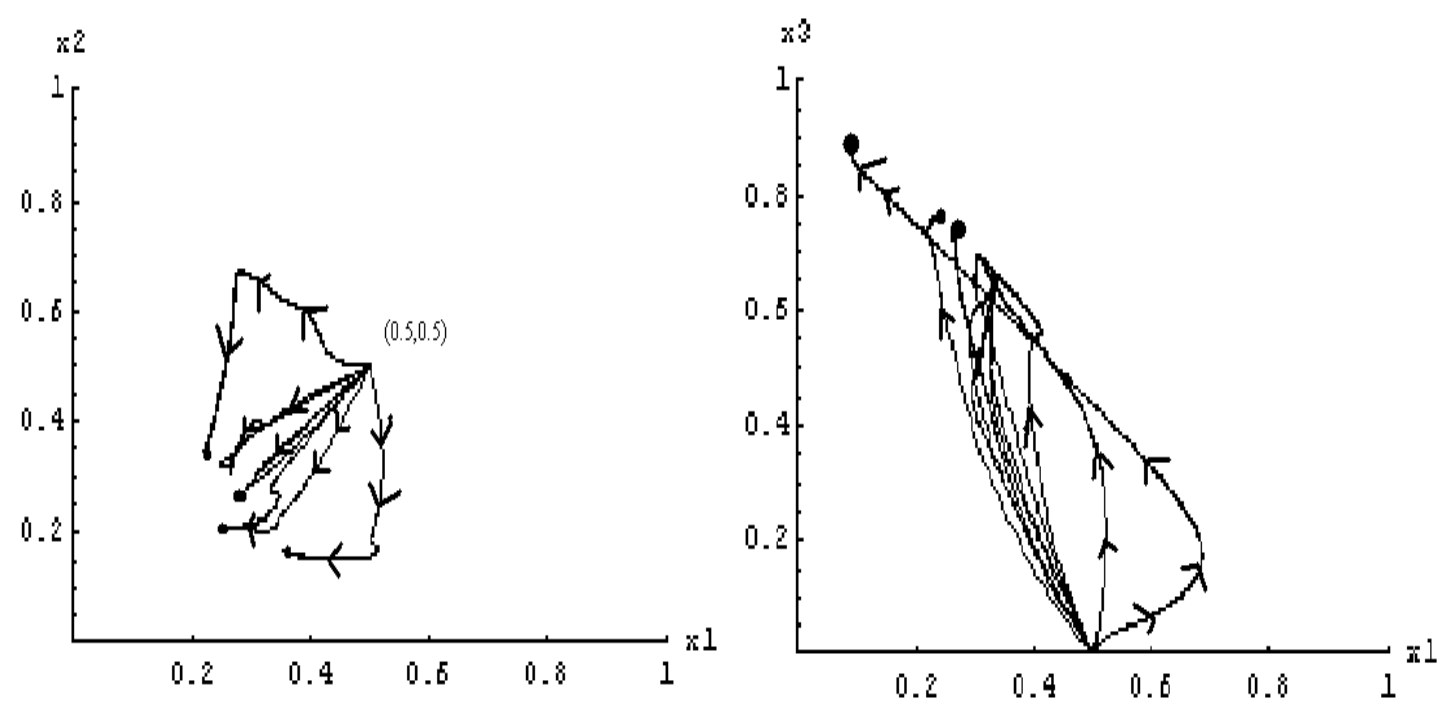

(e) Phase diagram $\left(x_{1 t}, x_{2 t}\right)$ in the presence of mutation

(f) Phase diagram $\left(x_{1 t}, x_{3 t}\right)$ in the presence of mutation

and recombination

and recombination

Figure 3. Phase diagrams for initial conditions: $x_{10}=0.5 x_{20}=0.5$, and $x_{30}=0$ 


\section{Dynamics of average cost and optimal diversity}

Maintaining a variety of technological options has benefits at the level of both markets and firms. For instance, firms that invest in a number of research projects are capable of modifying existing technologies more easily and applying them later across different products and markets at lower costs (Granstrand, 1998). Nevertheless, economists often emphasize the high costs associated with maintaining diversity, such as lost advantages of scale and specialization (i.e. increasing returns to scale, including traditional economies of scale); organizational costs associated with coordination and integration of multiple projects; and the cost of carrying out multi-disciplinary $\mathrm{R} \& \mathrm{D}$. One might think that the total cost of investments would be minimized if in each period investors allocate all investment to the cheapest technologies. However, this may not be true in the long run as it neglects the possibility of cost decreases through learning and $R \& D$, and new technologies emerging through recombinant innovation.

The profit motive alone is likely to be insufficient to provide entrepreneurs with incentives to innovate at the socially optimal rate (Berzel, 1968). In particular, where technology costs depend on cumulative installed capacity, producers may decide to postpone investing in initially expensive technologies, until investments by others reduce their unit cost. This resembles an Investor's Dilemma situation as described by Christenson (2003), where large companies are reluctant to invest in new technologies before they become profitable. However, without costly investments in installed capacity of new technologies, for instance, renewable energy plants, these technologies may never become cost-competitive.

In this section, we examine the effect of various investment heuristics on the dynamics of average cost of investments in alternative versions of the model. The conducted analysis can be informative about which investments strategies of individual entrepreneurs, captured by mutation and recombination, are socially optimal in the sense of ensuring a diversity of technologies at the lowest possible average cost of investments (at the industry level). In fact, governments have already attempted to encourage producers to diversify investments with various policy instruments. A relevant example here is the case of Renewable Obligations (RO) introduced in 2002 in the UK. It required electricity suppliers to deliver a certain percentage of their annual supply to final consumers from a list of renewable energy technologies. As a result, suppliers were obliged to buy a certain percentage of total energy from relatively expensive energy sources.

The average cost of investments is defined formally as an average of unit costs of capital weighted by shares of this capital in the industry at time $t: \Sigma_{i} x_{i t} c_{i t}$. Appendix A3 offers a derivation of recombination rate that minimises the average cost of investments, for three different versions of the model. Below, we illustrate numerically the evolution of the average 
cost of investments over time for different mutation and recombination values. The initial conditions are set as $a=b=g=1, c_{10}=0.1, \quad c_{20}=0.2, \quad c_{30}=0.4, x_{10}=x_{20}=0.5, x_{30}=0, \delta=0.5$, $\beta_{1}=\beta_{2}=0.05$, and $\beta_{3}=0.35$, which captures the case of a new, emerging technology with an initially high unit cost competing for adoption with two incumbent technologies with relatively low unit costs.

Figures 4-6 present, respectively, the results for the three versions of the model: with constant unit costs; with costs decreasing steadily and exogenously over time; and with costs following the learning curve. For the versions of the model with constant unit costs, a higher recombination rate (for a given mutation rate) in Figure 4a or a higher mutation rate (for a given recombination rate) in Figure $4 \mathrm{~b}$ contribute to a larger average cost of investments at any point of time. The reason is that investments in alternative technologies and research on recombinant innovation, as described by mutation and recombination, only distract capital from the cheapest technological option.

Similarly, in the model with unit costs falling steadily over time, higher recombination rates (for a given mutation rate) translate into higher average costs of investments at any point of time. On the other hand, for a given recombination rate, the effect of an increase in the mutation rate on the average cost depends on the time at which the latter is being evaluated. If the average cost is evaluated after $t>20$ (Figure $5 \mathrm{~b}$ ), the higher mutation rate results in a lower average cost of investments. This suggests that diversification of technologies by individual entrepreneurs can be socially beneficial (i.e. in terms of lowering the average cost of investments in the industry) if the time horizon of investments is sufficiently long.

In the model with costs decreasing along a learning curve, the effect of an increase in the recombination rate on the average cost depends on the time when the latter is evaluated. Generally, a higher recombination rate tends to lower the average cost over time (Figure 6a). On the other hand, for a given recombination rate, an increase in the mutation rate increases the average cost. This relates to the fact that if provided with sufficient learning opportunities, a new emerging technology may achieve a very low unit cost over time. Investments in diversification (in incumbent technologies) may slow down this process by diverting capital away from the technology with the highest potential for cost reduction. In the absence of such investments in diversification, the new technology is likely to dominate the market, reducing diversity of technologies therein (see Section 4.2), and moreover to achieve the lowest possible unit costs which in turn reduces the average cost of investments. In other words, a trade-off between diversity, recombinant innovation, and the cost of diversification is at stake here. To conclude, in the versions of the model with costs decreasing steadily over time the optimal strategy, in terms of minimizing investment costs, is to invest only in diversification of the investment portfolio (Figure 5a). In the model with cost reductions 
occurring along a learning curve, the lowest average cost of investments is achieved in the absence of investments in diversification. Here, the optimal strategy involves investing solely in recombinant innovation (Figure 6b).

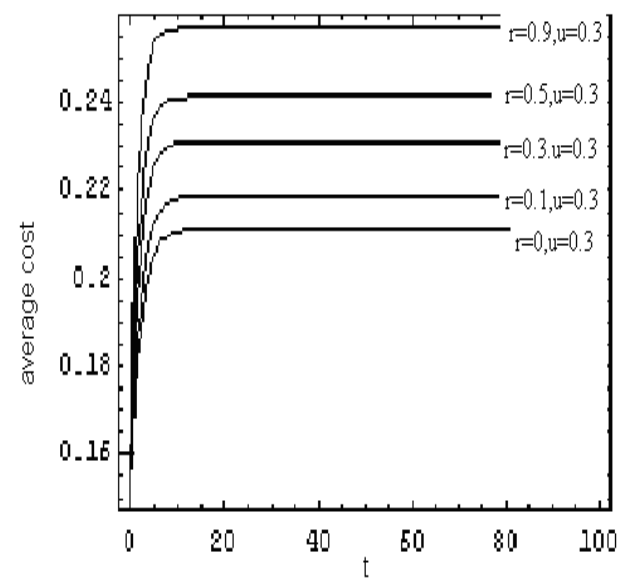

(a) $\mu=0.3$

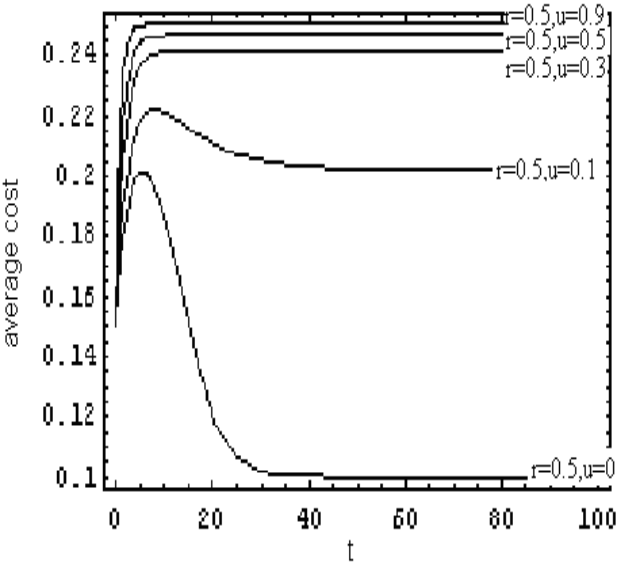

(b) $r=0.5$

Figure 4. Average costs over time for the version of the model with constant unit costs
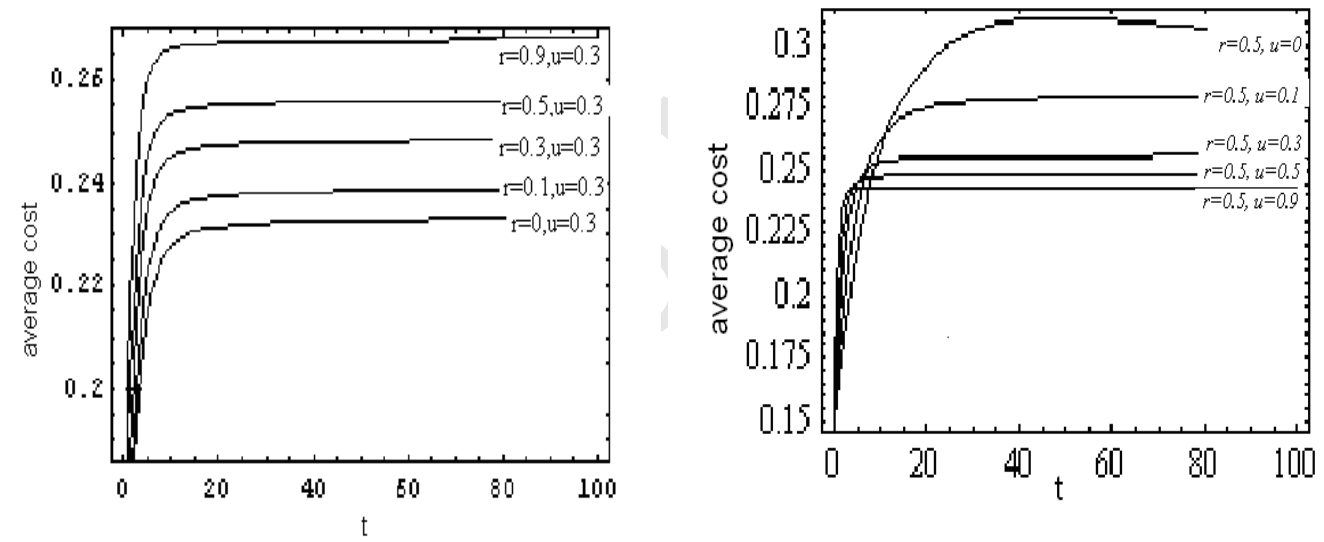

Figure 5. Average costs over time for the version of the model with unit costs decreasing steadily over time

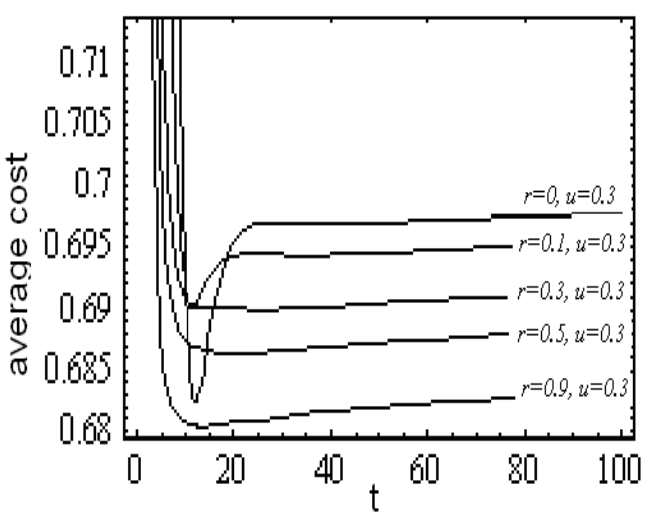

(a) $\mu=0.3$

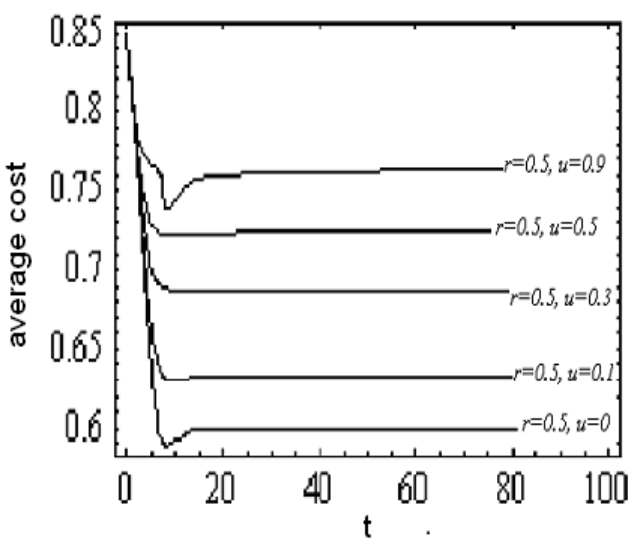

(b) $r=0.5$

Figure 6. Average costs over time for the version of the model with unit costs decreasing alone the learning curve 


\section{Conclusions}

Modeling the process of technological change through the method of replicator dynamics predominates in the literature on innovation and evolutionary economics. This approach depicts behavior of producers and investors as adopting above-average performing technologies, whose market shares then increase. Nevertheless, it ignores the possibility of mistakes by boundedly rational investors and costly experimentation with new variations and combinations of existing technologies, even though these are important and well-documented aspects of technological evolution. In the process of technological change, the presence of new solutions at a given moment of time depends on technological progress and market opportunities achieved up to that date. The latter are the result of progressive market selection over time. Since selection acts on existing variety, the processes of selection and variety creation are interdependent. This is, however, not captured by replicator dynamics.

The aim of this paper was to grasp the interaction between selection and innovation in the simplest possible way. With this purpose in mind, we proposed an extension of replicator dynamics with recombination and mutation. It gives rise to interactive innovation-selection dynamics. Until now, this approach has not received any attention in economics, even though it captures all aspects of evolution in the most simple, condensed way. The framework was interpreted here as describing a population of boundedly-rational entrepreneurs. In each period, they decide on the allocation of investment capital among different technological options. They tend to invest in capital associated with below-average cost technologies, just as under replicator dynamics. In addition, they devote a certain fraction of investments, captured by mutation and recombination, to alternative technologies and research on recombinant innovation. In this context, mutation and recombination are conceptual variables with concrete behavioral interpretation which depicts the heuristic decision rules of entrepreneurs. Mutation can capture a range of potential behaviors: namely, the inability of investors to perfectly assess the profitability of different technologies, costly experimentation, deliberate portfolio diversification, and risky investments in new technologies. Investments in recombinant innovation can stimulate the emergence of a new technological option, which is initially absent from the market. The model allows comparing the cases in which all firms behave as if they were rational (in the absence of mutation and recombination, i.e. pure replicator dynamics) and in which they are boundedly rational (in the presence of mutation and recombination, i.e. innovation-selection dynamics).

We studied evolutionary dynamics for three cases: namely, where selection operates on technologies characterized by constant costs; by costs that decrease steadily and exogenously over time; and by costs that change depending on the level of cumulative investments. The results revealed that, for each resulting model version, mutation enhances 
diversity. In the absence of mutation, a single technology typically ends up dominating the market. Thus, to stimulate the coexistence of technological options in the long run, experimenting with variations of existing technologies is recommendable. On the other hand, a high recombination rate increases the probability that a new technology emerges and will ultimately dominate investments, which may limit diversity. The role of recombination in ensuring coexistence of a variety of options is a new finding in the evolutionary-economics literature.

The results also suggest that the effect of mutation and recombination on the average costs of investments varies between alternative versions of the model. In the model with constant cost of capital, more investments in diversification and innovation research increases the average cost of investments in different technologies. Here, a socially optimal rate of investment in these innovation activities is zero. For an alternative model version, where costs change steadily over time, more investment in diversification decreases the average cost; while more investment in recombinant innovation typically increases it. These relationships are reversed where unit costs decrease along a learning curve. Here, the lowest possible average cost of investments was achieved in the absence of investments in diversification. The optimal, cost-minimizing strategy was investing solely in recombinant innovation. However, if all entrepreneurs adopt such a cost-minimising strategy, this can result in a new technology dominating the market, while reducing diversity of technologies.

The analysis of the properties of replicator dynamics extended with mutation and recombination provides insight into the process of induced technological change. Policymakers often face a trade-off between short- and long-term economic benefits, or between private and social benefits. Firms investing solely in the currently most profitable or cheapest technologies may give rise to socially suboptimal outcomes at the industry level (i.e. a high average cost of investments). The question arises how many scarce resources should be diverted from incumbent technologies towards alternatives and innovation research. It was shown here that the benefits from increasing returns (due to specialization) and from recombinant innovation (due to diverse options) depend on opportunities for cost reduction, investment heuristics of entrepreneurs, and the time horizon.

Possible extensions of the model involve studying multi-parent recombination and inclusion of a stochastically or endogenously changing number of dimensions in which components of technologies are being recombined. In addition, it might be interesting to compare patterns of change from our model with empirical data. This would allow examining whether our model provides a better fit of real-world data than simple replicator dynamics. 


\section{References}

Arifovic, J., 1994. Genetic algorithm learning and the cobweb model. Journal of Economic Dynamics and Control 18: 3-28.

Arifovic, J., 1995. Genetic algorithm learning and inflationary economics. Journal of Monetary Economics 36: 219-243.

Arrow, K.J., 1962. The economic implications of learning by doing. Review of Economic Studies 29, 155-173.

Aversi, R., Dosi, G., Fagiolo, G., Meacci, M., Olivetti, C., 1997. Demand dynamic with socially evolving preferences. IIASA International Institute for Applied System Analysis Interim Report IR-97-081.

Axelrod, R., 1987. The evolution of strategies in the iterated prisoners dilemma. In: L., David, (Editor), Genetic Algorithms and Simulated Annealing. Pitman, Boston, MA, pp. 32-41.

Barton, N.H., 1995. A general model for the evolution of recombination. Genetical Research 65, 123 144.

Birchenhall, C.R., 1995. Review: genetic algorithms, classifier systems and genetic programming and their use in the models of adaptive behaviour and learning. Economic Journal 105, 788-795.

Birchenhall, C.R., N. Kastrinos, Metcalfe, S., 1997. Genetic algorithms in evolutionary modelling. Journal of Evolutionary Economics 7, 375-393.

Boerlijst, M.C., S. Bonhoeffer, Nowak, M.A., 1996. Viral Quasi-Species and Recombination. Proceedings of the Royal Society London B 263, 1577-1584.

Bomze, I., Burger, R., 1995. Stability by mutation in evolutionary games. Games and Economic Behaviour 11, 146-172.

Berzel, Y., 1968. Optimal timing of innovations. The Review of Economics and Statistics 50: 348-355.

Bull, J.J., L.A. Meyers, Lachmann, M., 2005. Quasispecies Made Simple. Computational Biology 1, 450-461.

Bulut, H., Moschini, G.C., 2005. Patents, trade secrets and the correlation among R\&D projects. Economic Letters 91, 131-137.

Canning, D., 1992. Average behaviour in learning models. Journal of Economic Theory 57, 442-472.

Clayton, M.C., 2003. The Innovator's Dilemma. Harper Collins Publisher, New York.

Curzon Price, T., 1997. Using co-evolutionary programming to stimulate strategic behaviours in markets. Journal of Evolutionary Economics 7: 219-254.

Dasgupta, P., Maskin, E., 1987. The simple economics of research portfolios. Economic Journal 97, 581-596.

Dawid, H., Kopel, M., 1998. On economic applications of the genetic algorithm: a model of the cobweb type. Journal of Evolutionary Economics 8: 297-315.

Diamond, J., 2005. Guns, Germs and Steel. Vintage Books, London.

EIA 2008. Annual Energy Outlook. The Energy Information Administration, The U.S. Department of Energy.

Eiben, A.E., Smith, J.E., 2003. Introduction To Evolutionary Computing, Springer.

Eigen, M., 1971. Self-organization of matter and the evolution of biological macromolecules. Naturwiss. 58, 465-523.

Eigen, M., Schuster, P., 1979. The Hypercycle: A Principle of Natural Self-Organization. SpringerVerlag, Berlin.

Feldman, M.W., F.B. Christiansen, Brooks, L.D., 1980. Evolution of recombination in a constant environment. Proceedings of the National Academy of Science. USA 77, 4838-4841.

Fleming, L., Sorenson, O., 2001. Technology as a complex adaptive system. Res. Pol. 30, 1019-1039.

Foster, D., Young, P., 1990. Stochastic evolutionary games. Theoretical Population Biology 38, 219232.

Friedman, M. 1953. On the methodology of positive economics. In: M. Friedman, Essays in Positive Economics. University of Chicago Press, Chicago.

Granstrand, O., 1998. Towards a theory of the technology-based firm. Research Policy 27, 465-489.

Hadeler, K.P., 1981. Stable polymorphisms in a selection model with mutation. SIAM Journal Applied Mathematics 41, 1-7.

Hofbauer, J., 1985. The selection mutation equation. Journal of Theoretical Biology. 23, 41-53.

Hofbauer, J., Sigmund, K., 2003. Evolutionary game dynamics. Bulletin of the American Mathematical Society 4, 479-519.

Iwai, K., 1984a. Schumpeterian dynamics, part I: evolutionary model of innovation and imitation. Journal of Economic Behaviour and Organization 5, 159-90.

Iwai, K., 1984b. Schumpeterian dynamics, part II: Technological progress. Firm growth and economic selection. Journal of Economic Behaviour and Organisation 5, 321-51. 
Jacobi, M.N., Nordahl, M. 2006. Quasispecies and recombination. Theoretical Population Biology 70(4), 479-485.

Jordan, D.W., Smith, P., 2007. Nonlinear Ordinary Differential Equations. Oxford University Press, Oxford ( $4^{\text {th }}$ edition).

Kandori, S.A., G.J. Mailath, Rob, R., 1993. Learning, Mutations, and Long Run Equilibrium in Games. Econometrica 61, 29-56.

Kimura, M., 1967. Evolutionary rate at the molecular level. Nature 217: 624-626.

Komarowa, N., 2004. Replicator-mutator equation, universality property and population dynamics of learning. Journal of Theoretical Biology 230, 227-239.

Kwasnicki, W., Kwasnicka, H., 1992. Market innovation competition: an evolutionary model of industrial dynamics. Journal of Economic Behaviour and Organization 19: 343-368.

Loomes, G., Sugden, R., 2000. Incorporating a stochastic element into decision theories. European Economic Review 39: 641-648.

Meltcafe, J.S., 1988. The diffusion of innovations: an interpretative survey. In: Dosi, G., Freeman, C., Nelson, R., Silverberg, G., Soete, L., (eds) Technical change and economic theory. Pinter Publishers, London, pp 560-589.

Miller, J.H., 1996. The coevolution of automata in the repeated prisoners dilemma. Journal of Economic Behaviour and Organization 29: 87-112.

Mokyr, J., 1990. The Lever of the Riches: Technological Creativity and Economic Progress. Oxford University Press, Oxford.

Nelson, R., Winter, S., 1982. An Evolutionary Theory of Economic Change, Cambridge MA: Harvard University Press.

Nowak, M.A., 1992. What is a quasi-species? Trends in Ecology and Evolution 7, 118-121.

Nowak, M.A., 2006. Evolutionary Dynamics. Exploring the Equations of Life. Harvard University Press, Cambridge, MA.

Nowak, M.A., Komarova, N.L., Niyogi, P., 2001. Evolution of universal grammar. Science 291, $114-$ 118.

Nowak., M.A., Komarova, N.L., Niyogi, P., 2002. Computational and evolutionary aspects of language. Nature 417, 611-617.

Nowak, M., Sigmund K., 1990. The evolution of stochastic strategies in the prisoner's dilemma. Acta Applied Mathematics 20, 247-265.

Nowak, M., Sigmund K., 2004. Evolutionary dynamics in biological games. Science 3030, 796-798.

Olsson, O., Frey B.S., 2002. Entrepreneurship as recombinant growth. Small Business Economics 19, 69-80.

Page, K., Nowak M., 2002. Unifying evolutionary dynamics. Journal of Theoretical Biology 219, 9398.

Safarzynska, K., van den Bergh J.C.J.M., 2010. Evolutionary modelling in economics: a survey of methods and building blocks. Journal of Evolutionary Economics 20(3), 329-373.

Samuelson, L., 1997. Evolutionary Games and Equilibrium Selection. The MIT Press, Cambridge, MA.

Schuster, P., Swetina, J., 1988. Stationary mutant distribution and evolutionary optimization. Bulletin of Mathematical Biology 50, 635-660.

Saviotti, P.P., Mani, G.S., 1995. Competition, variety and technological evolution: a replicator dynamics model. Journal of Evolutionary Economics 5, 369-392.

Saviotti, P.P., Pyka, A., 2004. Economic development by the creation of new sectors. Journal of Evolutionary Economics 14:1-35.

Silverberg, G., Dosi, G., Orsenigo, L., 1988. Innovation diversity and diffusion: a self-organization model. Economic Journal 98:1032-54.

Silverberg, G., Lehnert, D., 1993. Long waves and 'evolutionary chaos' in a simple Schumpeterian model of embodied technical change. Structural. Change and Economic Dynamics 4, 9-37.

Soete, L., Turner, R., 1984. Technology diffusion and the rate of technological change. The Economic Journal 375: 612-623.

Stadler, P.F., Schuster, P., 1992. Mutation in autocatalytic reaction networks- an analysis based on perturbation theory. Journal of Mathematical Biology 30, 597-632.

Taylor, P.D., Jonker, L., 1978. Evolutionary stable strategies and game dynamics. Mathematical Bioscience 40, 145-156.

Tsur, Y., Zemel, A., 2007. Towards endogenous recombinant growth. Journal of Economic Dynamics and Control 31, 3459-3477.

van den Bergh, J.C.J.M., 2008. Optimal diversity: Increasing returns versus recombinant innovation. Journal of Economic Behaviour and Organization 68, 565-580. 
Watson, R.A., 2006. Compositional Evolution: The Impact of Sex, Symbiosis, and Modularity on the Gradualist Framework of Evolution. The MIT Press, Cambridge, MA.

Weitzman, M.L., 1998. Recombinant growth. Quarterly Journal of Economics 113, 331-360.

Wiggins, S., 2003. Introduction to Applied Nonlinear Dynamical Systems and Chaos. Springer Berlin Heidelberg: New York ( $2^{\text {nd }}$ edition).

Willensdorfer, M., Nowak, M., 2005. Mutation in evolutionary games can increase average fitness at equilibrium. Journal of Theoretical Biology 237, 355-362.

Windrum, P., 2007. Neo-Schumpeterian simulation models. In: Hanusch, H., Pyka, A, (eds) Elgar Companion to Neo-Schumpeterian Economics, Edward Elgar, UK, pp 405-439.

Windrum, P., Birchenhall, C.T., 1998. Is life cycle theory a special case?: dominant designs and emergence of market niches through co-evolutionary learning. Structural Change and Economic Dynamics 9: 109-134.

Windrum, P., Birchenhall, C.T., 2005. Structural change in the presence of network externalities: a coevolutionary model of technological successions. Journal of Evolutionary Economics 15: 123148.

Winter, S.G., 1964. Economic 'natural selection' and the theory of the firm. Yale Economic Essays 4, 225-72.

Wolfram Research Inc., 2001. Mathematica, Version 4.1, Champaign, IL.

Yildizoglu, M., 2002. Competing R\&D Strategies in an Evolutionary Industry Model. Computational Economics 19, 51-65.

Young, H.P., 1993. The evolution of conventions. Econometrica 61, 57-84.

Young, H.P., 1996. The economics of conventions. Journal of Economic Perspective 10, 105-122. 
Acknowledgments: We would like to thank Paolo Zeppini and two anonymous referees for comments and suggestions.

\section{APPENDIX}

\section{A1. Parameter values}

Table A1. Parameter settings corresponding to different trajectories depicted in Figures 2a-f, 6a-f and $8 a-f$.

\begin{tabular}{|c|c|c|c|c|}
\hline \multirow[t]{2}{*}{ Trajectory } & \multirow{2}{*}{$\begin{array}{c}\text { Fixed parameters per trajectory } \\
\qquad \begin{array}{c}\text { (always } a=b=g=1, \\
\left.\beta_{1}=\beta_{2}=0.05, \text { and } \beta_{3}=0.35\right)\end{array}\end{array}$} & \multicolumn{3}{|c|}{ Variation in parameter values } \\
\hline & & $\begin{array}{c}\text { Figures } 2 \mathrm{a}, \mathrm{b}, \\
6 \mathrm{a}, \mathrm{b} \text { and } \\
8 \mathrm{a}, \mathrm{b} \\
\text { (always } \mu=0 \text { ) }\end{array}$ & $\begin{array}{c}\text { Figures } 2 \mathrm{c}, \mathrm{d} \text {, } \\
6 \mathrm{c}, \mathrm{d} \\
\text { and } 8 \mathrm{c}, \mathrm{d} \\
\text { (always } r=0 \text { ) }\end{array}$ & $\begin{array}{c}\text { Figures } 2 \mathrm{e}, \mathrm{f}, \\
6 \mathrm{e}, \mathrm{f} \\
\text { and } 8 \mathrm{e}, \mathrm{f}\end{array}$ \\
\hline 1 & $\mathrm{c}_{10}=0.1, \mathrm{c}_{20}=0.2, \mathrm{c}_{30}=0.4, \delta=0.5$, & $\mathrm{r}=0.5$ & $\mu=0.6$ & $\mathrm{r}=0.5, \mu=0.6$ \\
\hline 2 & $\mathrm{c}_{10}=0.4, \mathrm{c}_{20}=0.2, \mathrm{c}_{30}=0.4, \delta=0.25$ & $\mathrm{r}=0.15$ & $\mu=0.3$ & $\mathrm{r}=0.15, \mu=0.3$ \\
\hline 3 & $\mathrm{c}_{10}=0.2, \mathrm{c}_{20}=0.2, \mathrm{c}_{30}=0.4, \delta=0.5$ & $\mathrm{r}=0.2$ & $\mu=0.6$ & $\mathrm{r}=0.2, \mu=0.6$ \\
\hline 4 & $\mathrm{c}_{10}=0.1, \mathrm{c}_{20}=0.5, \mathrm{c}_{30}=0.2, \delta=0.1$ & $\mathrm{r}=0.2$ & $\mu=0.2$ & $\mathrm{r}=0.2, \mu=0.2$ \\
\hline 5 & $\mathrm{c}_{10}=0.1, \mathrm{c}_{20}=0.2, \mathrm{c}_{30}=0.4, \delta=0.5$ & $\mathrm{r}=0.9$ & $\mu=0.2$ & $\mathrm{r}=0.9, \mu=0.2$ \\
\hline 6 & $\mathrm{c}_{10}=0.3, \mathrm{c}_{20}=0.2, \mathrm{c}_{30}=0.9, \delta=0.5$ & $\mathrm{r}=0.01$ & $\mu=0.1$ & $\mathrm{r}=0.01, \mu=0.1$ \\
\hline 7 & $\mathrm{c}_{10}=0.9, \mathrm{c}_{20}=0.2, \mathrm{c}_{30}=0.1, \delta=0.6$ & $\mathrm{r}=0.7$ & $\mu=0.4$ & $\mathrm{r}=0.7, \mu=0.4$ \\
\hline $8^{*}$ & $\mathrm{c}_{10}=0.1, \mathrm{c}_{20}=0.2, \mathrm{c}_{30}=0.7, \delta=0.9$ & $\mathrm{r}=0.2$ & $\mu=0.9$ & $\mathrm{r}=0.2, \mu=0.9$ \\
\hline 9 & $\mathrm{c}_{10}=0.7, \mathrm{c}_{20}=0.1, \mathrm{c}_{30}=0.4, \delta=0.9$ & $\mathrm{r}=0.8$ & $\mu=0.7$ & $\mathrm{r}=0.8, \mu=0.7$ \\
\hline 10 & $\mathrm{c}_{10}=0.5, \mathrm{c}_{20}=0.2, \mathrm{c}_{30}=0.4, \delta=0.3$ & $\mathrm{r}=0.8$ & $\mu=0.5$ & $\mathrm{r}=0.8, \mu=0.5$ \\
\hline
\end{tabular}

Note:* Trajectory 8 is not depicted in Figures $8 \mathrm{c}$ to $8 \mathrm{f}$, as the dynamics result in values of technology shares of investments falling outside the plausible range $[0,1]$.

\section{A2. Eigenvalues}

To examine the stability of the above equilibria, we checked the eigenvalues of a linear approximation of the system. In general, if all the eigenvalues of the linear system have negative real parts, then the linear approximation is asymptotically stable, and so is the nonlinear system (Jordan and Smith, 2007). If at least one eigenvalue has a positive real part, then the equilibrium point will be unstable. Table A2 shows the eigenvalues for each equilibrium. 
Table A2. Eigenvalues corresponding to solutions 1-4 of Table 1

\begin{tabular}{|l|l|}
\hline Solution & Eigenvalues $\left(\lambda_{1}, \lambda_{2}, \lambda_{3}\right)$ \\
\hline 1 & $\left(f_{1}-f_{3}, f_{2}-f_{3},-f_{3}\right)$ \\
\hline 2 & $\left(-f_{2},-f_{2}+f_{3}, f_{1}-f_{2}-\delta r\right)$ \\
\hline 3 & $\left(-f_{1},-f_{1}+f_{3},-f_{1}+f_{2}-r(\delta \alpha-1)\right)$ \\
\hline 4 & $\begin{array}{l}\left(-\frac{-f_{1}\left(f_{2}+f_{3}(\delta-1)+f_{3}\left(f_{2}+r(\delta-1)\right) \delta\right.}{f_{3}-f_{1} \delta+(\delta-1)\left(f_{2}+\delta r\right)},\right. \\
\frac{\left(f_{1}-f_{3}\right)\left(f_{2}-f_{3}\right) r-\sqrt{\left(f_{1}-f_{3}\right)\left(f_{2}-f_{3}\right) r\left(\left(f_{1}-f_{3}\right)\left(f_{2}-f_{3}\right) r-4\left(f_{1}-f_{2}-\delta r\right)\left(f_{1}-f_{2}+r-\delta r\right)\left(-f_{3}+f_{1} \delta-(\delta-1)\left(f_{3}+r \delta\right)\right.\right.}}{2 r\left(f_{3}-f_{1} \delta+(\delta-1)\left(f_{2}+r \delta\right)\right)} \\
\frac{\left(f_{1}-f_{3}\right)\left(f_{2}-f_{3}\right) r+\sqrt{\left(f_{1}-f_{3}\right)\left(f_{2}-f_{3}\right) r\left(\left(f_{1}-f_{3}\right)\left(f_{2}-f_{3}\right) r-4\left(f_{1}-f_{2}-\delta r\right)\left(f_{1}-f_{2}+r-\delta r\right)\left(-f_{3}+f_{1} \delta-(\delta-1)\left(f_{3}+r \delta\right)\right.\right.}}{2 r\left(f_{3}-f_{1} \delta+(\delta-1)\left(f_{2}+r \delta\right)\right)}\end{array}$ \\
\hline
\end{tabular}

\section{A3. Derivation of recombination rates}

The recombination and mutation rates that minimize the average cost of the system in the equilibrium implies:

$$
\frac{\partial \sum_{i} x_{i} c_{i}}{\partial r}=0 \quad \text { or } \frac{\partial \sum_{i} x_{i} c_{i}}{\partial \mu}=0,
$$

with $\mu=0$ and $r=0$, respectively.

The exercise of deriving the optimal recombination and mutation rates can be only conducted where the exact solutions of the system are found. For the model version with constant unit costs, and in the absence of mutation, the optimal recombination rate that minimizes the average cost for the solution that corresponds to the coexistence of different technological options (solution 5 in Table 1 ) is:

$$
r=\frac{c_{30}-c_{20}+\left(1-c_{10}\right) \delta-\left(1-c_{20}\right) \delta}{\left(-\delta+\delta^{2}\right)} .
$$

Here, the optimal recombination rate depends on the weights $\delta$ and $1-\delta$ at which Technologies 1 and 2 are recombined and on the relative costs of technologies. ${ }^{9}$

In the version of the model with unit costs decreasing over time, and in the absence of mutation, the optimal recombination rate that maximizes the average fitness for the solution corresponding to the coexistence of three options (solution 6 in Table 2) is given by:

$\mathrm{r}=\frac{-a b c_{20}+c_{10} c_{20}+a b c_{30}-c_{10} c_{30}-a g t c_{20}+a g t c_{30}-a b c \delta+a b c_{20} \delta+c_{10} c_{30} \delta-a c_{10} g t \delta+a g t c_{20} \delta}{(b+g t)\left(a b+a g t-c_{30}\right)(\delta-1) \delta}$.

Here, in the limit of $t \rightarrow \infty, r=0$.

\footnotetext{
${ }^{9}$ If a single technology $i$ dominates a market (Solution 2-4 in Table 1), the average costs are equal to $c_{i 0} x_{i}$, i.e. unaffected by $r$.
} 